\title{
The Optimal Tax Treatment of Housing Capital in the Neoclassical Growth Model
}

\author{
Essi Eerola \\ University of Helsinki and HECER \\ and \\ Niku Määttänen \\ The Research Institute of the Finnish Economy and CEBR
}

Discussion Paper No. 178

August 2007

(First version: July 2005)

ISSN 1795-0562

HECER - Helsinki Center of Economic Research, P.O. Box 17 (Arkadiankatu 7), FI-00014 University of Helsinki, FINLAND, Tel +358-9-191-28780, Fax +358-9-191-28781, E-mail info-hecer@helsinki.fi, Internet www.hecer.fi 


\title{
The Optimal Tax Treatment of Housing Capital in the Neoclassical Growth Model*
}

\begin{abstract}
In a dynamic setting, housing is both an asset and a consumption good. But should it be taxed like other forms of consumption or like other forms of saving? We consider the optimal taxation of the imputed rent from owner housing within a version of the neoclassical growth model. We find that the optimal tax rate on the imputed rent is quite sensitive to the constraints imposed on the other tax instruments. In general, it is not optimal to tax the imputed rent at the same rate as business capital income.
\end{abstract}

JEL Classification: H21, E21

Keywords: housing, capital taxation, optimal taxation.

\section{Essi Eerola}

Department of Economics

University of Helsinki

P.O. Box 17 (Arkadiankatu 7)

FI-00014 University of Helsinki

FINLAND

e-mail: essi.eerola@helsinki.fi
Niku Määttänen

ETLA

Lönnrotinkatu $4 \mathrm{~B}$

FI-00120 Helsinki

FINLAND

e-mail: niku.maattanen@etla.fi

\footnotetext{
* We thank Jouko Vilmunen for helpful discussions. We also thank Markus Haavio, Seppo Honkapohja, Karlo Kauko, Erkki Koskela, Henry Ohlsson, and Matti Viren for useful comments and suggestions. This research project was started during Eerola's visit at the Bank of Finland Research Department. She wishes to thank the Department for its hospitality during her visit. Both authors gratefully acknowledge financial support from the Yrjö Jahnsson Foundation.
} 


\section{Introduction}

The tax treatment of housing is an important fiscal question because housing wealth constitutes a large share of all household wealth. A common view in the public finance literature is that housing enjoys a tax favored status in most western economies, mainly because the return to owner housing, the imputed rent, usually goes untaxed while the return to business capital is taxed at a relatively high effective tax rate. ${ }^{1}$

Several studies have assessed the welfare consequences of a tax reform that removes this tax favored status of owner housing by setting an equal tax rate on the imputed rent and business capital income. Using quantitative dynamic general equilibrium models, Gahvari (1985), Skinner (1996), and Gervais (2002), among others, have shown that such a reform would lead to substantial efficiency gains. ${ }^{2}$

While these previous studies show that the current tax status of housing is highly distortionary, they do not aim to determine what the optimal tax treatment of housing is and how it depends on the overall tax system. Of course, it need not be optimal to tax the imputed rent at the same rate as business capital income. ${ }^{3}$ Since the return to owner housing is a utility flow, it is not clear whether this return should be treated like other forms of saving rather than like other forms of consumption.

The previous studies also typically consider only steady state effects of tax reforms. ${ }^{4}$ As is often the case with dynamic optimal taxation, neglecting the transition may give very misleading welfare results. Moreover, the optimal tax rates are time varying and it is of interest to see how they should evolve over time.

\footnotetext{
${ }^{1}$ See Hendershott and White (2000) for an international comparison of housing's tax status.

${ }^{2}$ Other studies that also consider the efficiency and welfare effects of the tax favored status of housing include Gahvari (1984), Slemrod (1982), Berkovec and Fullerton (1992), Hendershott and Won (1992), Poterba (1992), and Bye and Åvitsland (2003). Turnovsky and Okuyama (1994) focus solely on capital accumulation. See also Englund (2003) for general discussion on housing taxation.

${ }^{3}$ Gahvari $(1984,1985)$ touches upon this issue but does not determine the optimal tax structure.

${ }^{4}$ Exeptions are Skinner (1996) and Eerola and Määttänen (2006).
} 
In this paper, we analyze the optimal tax treatment of housing in a dynamic general equilibrium setting. We employ a version of the neoclassical growth model with a representative household. Housing is introduced following Greenwood and Hercowitz (1991). Although the model is relatively simple, it captures the intertemporal savings-consumption decision and the general equilibrium effects of capital taxation that we are interested in. As far as we know, we are the first to consider housing taxation as a part of an optimal taxation problem in a dynamic general equilibrium setting. ${ }^{5}$

We seek to answer two questions: First and foremost, what is the optimal tax treatment of housing and how it depends on the set of available tax instruments. Second, what is the optimal tax structure if housing cannot be taxed. Our motivation for this second question is that most countries simply do not have a tax on the imputed rent. ${ }^{6}$ This is a restriction on the set of available tax instruments which should be taken into account when designing optimal tax policies. Analyzing the case where housing taxation is ruled out also allows to compare the welfare gains of optimal tax reforms with and without the possibility to tax housing. This gives us a measure of the welfare cost of not taxing housing.

Formally, we analyze a Ramsey problem for a government that finances government expenditure by a set of flat rate taxes. The government is assumed to be able to commit to future tax policies. The solution to the Ramsey problem is a tax reform which is optimal given the initial state of the economy, individual optimization, and the available tax instruments. This approach takes transitionary dynamics properly into account.

We formulate the optimal taxation problem following the line of research represented by Judd (1985), Chamley (1986), Jones et al. (1997), and Atkeson et al. (1999), among

\footnotetext{
${ }^{5}$ Cremer and Gahvari (1998) study the optimal taxation of housing in a very different context. In their static model with incomplete information, the government may use differentiated housing taxes so as to separate between different consumer types.

${ }^{6}$ Property taxes are common. However, they are often regarded as user fees for publicly provided services rather than taxes on housing, especially when they are collected at the communal level as in the US (see e.g. the discussion in Fullerton, 1987).
} 
others. Our benchmark case follows Coleman (2000). The government can tax business and housing capital, labor, and consumption but is not allowed to subsidize labor. The role for consumption taxation is well defined because the representative household receives part of its revenues as lump-sum transfers. We then impose further restrictions on the set of available tax instruments. First, we restrict the consumption tax to be at a fixed, predetermined level. This case covers the more standard set-up where the government can tax only labor and capital. Second, we rule out taxing housing.

In the benchmark case, in the long run, the optimal tax rate on business capital income is strictly negative and the optimal tax rate on consumption is strictly positive. While we cannot analytically determine the sign of the optimal long run tax rate on the imputed rent, we can show that when the utility function is logarithmic, it is strictly larger than the tax rate on business capital income. Our numerical results show that in the short run, both the imputed rent and business capital income should be taxed at very high rates. In the long run, the optimal tax rate on business capital income is slightly below zero while the optimal tax rates on the imputed rent and consumption remain relatively high.

The optimal tax treatment of housing crucially depends on the availability of a consumption tax. This can be clearly seen in the case where consumption tax is fixed. In a special case with a logarithmic utility function and without consumption taxation and lump-sum transfers to households, the optimal tax rate on housing is always equal to the optimal tax rate on business capital income. In the long run, both taxes rates should then be zero.

Ruling out housing taxation altogether changes the optimal tax treatment business capital income quite substantially. In particular, when housing cannot be taxed, the tax rate on business capital income does not feature the usual dynamics with very high tax rates in the first periods and a rapid convergence to the new steady state tax rate. Instead, it starts to diminish from the very first periods onwards and converges to its long run level very slowly. Related to this result, we find that the welfare cost of not taxing housing is large. With our benchmark calibration, the welfare gain from the optimal tax reform falls by over $40 \%$ if 
housing cannot be taxed.

We proceed as follows. In the next section we describe the economy and discuss briefly the case where the government can use a full set of linear taxes with the ability to tax leisure. In this case, it is easy to characterize the optimal tax system essentially because the first best solution can be obtained. In section 3, we analytically characterize the optimal tax structure under various constraints to the set of available tax instruments. We present and discuss our numerical results in section 4 . We conclude in section 5 .

\section{The model}

We consider a deterministic model with an infinitely lived representative household that derives utility from the consumption of a consumption good, housing services, and leisure. The production side consists of firms that employ business capital and labor to produce output goods which can be turned into investment and consumption goods. There is a government that finances public expenditures with flat-rate taxes.

\subsection{Firms}

Every period $t$, a representative firm employs business capital, $k_{t}$, and labor, $n_{t}$, to produce output goods, $y_{t}$. The production function is

$$
y_{t}=f\left(k_{t}, n_{t}\right) .
$$

We assume that the production function features constant returns to scale and that $f_{k n}>0$ for all $k>0$ and $n>0 .{ }^{7}$ The firm's first-order conditions for profit maximization imply that the before-tax returns to business capital and labor are given by their marginal productivities, that is,

$$
r_{t}=f_{k_{t}}-\delta_{k}
$$

\footnotetext{
${ }^{7}$ We denote $\frac{\partial}{\partial k_{t}} f\left(k_{t}, n_{t}\right)=f_{k_{t}}$ and similarly for other derivatives throughout the paper.
} 
and

$$
w_{t}=f_{n_{t}},
$$

where $\delta_{k}$ is the depreciation rate of business capital. The output good may be costlessly converted into consumption good, business capital, and housing capital.

\subsection{The household's problem}

A representative household is endowed with one unit of time every period. It derives utility from consumption, $c$, leisure, $1-n$, and the stock of housing capital, $h$. The periodic utility function is $u(c, h, n)$. The utility function is strictly increasing in consumption and housing and strictly decreasing in labor, strictly concave, and satisfies the Inada conditions.

This utility function can be interpreted as a reduced form of the preference structure in Greenwood and Hercowitz (1991), where households derive utility from the consumption of goods and services produced in the market and goods and services produced at home, or 'home production'. Home production is created by combining housing capital and time not allocated to market production. ${ }^{8}$

Some of our analytical results concern the logarithmic and separable special case where

$$
u(c, h, n)=\alpha^{c} \log (c)+\alpha^{h} \log (h)+\left(1-\alpha^{c}-\alpha^{h}\right) \log (1-n) .
$$

This is also the utility function employed in deriving our main quantitative results. With this utility function, the elasticity of substitution between housing and consumption is equal to one. As noted by Kydland (1985), it is therefore consistent with the fact that historically US households have spent a roughly constant fraction of their overall expenditures in housing even though the relative price of housing has declined over time.

\footnotetext{
${ }^{8} \mathrm{~A}$ more general formulation would allow for allocating time to 'leisure', 'home production' and 'market production'. For studies using this approach, see e.g. Gomme et al. (2001), Baxter and Jerman (1999) and McGrattan et al. (1997). The two approaches result in the same allocations under a logarithmic specification. For more discussion on this issue, see Greenwood et al. (1995).
} 
The household can use both housing and business capital as a savings vehicle. The maximization problem of the household in period 1 is

$$
\max \sum_{t=1}^{\infty} \beta^{t-1} u\left(c_{t}, h_{t}, n_{t}\right)
$$

subject to the intertemporal budget constraint

$$
\sum_{t=1}^{\infty} p_{t}\left[\left(1+\tau_{t}^{c}\right) c_{t}+k_{t+1}+h_{t+1}-R_{t} k_{t}-\left(1-\tau_{t}^{n}\right) n_{t} w_{t}-g_{2}-R_{t}^{h} h_{t}\right] \leq 0
$$

where

$$
R_{t}=1+\left(1-\tau_{t}^{k}\right) r_{t}
$$

and

$$
R_{t}^{h}=1-\delta_{h}-\tau_{t}^{h} r_{t}
$$

The tax rates on consumption, business capital income, imputed rent, and labor income are denoted by $\tau^{c}, \tau^{k}, \tau^{h}$, and $\tau^{n}$, respectively. We set the price of one unit of the consumption good in period 1 equal to one. The price of period $t$ consumption in terms of period 1 consumption is denoted by $p_{t}$. Lump-sum transfers from the government are denoted by $g_{2}$. Parameter $\delta_{h}$ is the depreciation rate of housing capital.

Housing taxation is based on the imputed rent, which is defined as the rental price of housing services. If rental markets existed, the return to rental housing should equal the return to business capital. Thus, the rental price of housing would be $r_{t}+\delta_{h}$, assuming that landlords pay for the depreciation and that the tax rate on rental income equals the tax rate on business capital income. The tax base for an amount $h_{t}$ of housing capital is the imputed rent net of depreciation, i.e. $r_{t} h_{t} \cdot{ }^{9}$

\footnotetext{
${ }^{9}$ The tax rate on the imputed rent should be understood as the overall effective tax rate on housing. Alternatively, and equivalently, housing taxation could take the form of a property tax.
} 
The first-order conditions characterizing individually optimal behavior may be written as

$$
\begin{aligned}
u_{c_{t}} \eta_{t}\left(1-\tau_{t}^{n}\right) w_{t}+u_{n_{t}} & =0 \\
u_{c_{t}} \eta_{t}-\beta u_{c_{t+1}} \eta_{t+1} R_{t+1} & =0 \\
\beta u_{h_{t+1}}-u_{c_{t}} \eta_{t}+\beta u_{c_{t+1}} \eta_{t+1} R_{t+1}^{h} & =0
\end{aligned}
$$

where $\eta_{t}=\frac{1}{1+\tau_{t}^{c}}$.

\subsection{Government}

Each period, total government expenditure is $g=g_{1}+g_{2}$ where $g_{1}$ denotes public consumption and $g_{2}$ is a transfer to the households. The budget need not be balanced on a period by period basis. The government faces the following intertemporal budget constraint:

$$
\sum_{t=1}^{\infty} p_{t}\left[\tau_{t}^{c} c_{t}+\tau_{t}^{k} r_{t} k_{t}+\tau_{t}^{n} n_{t} w_{t}+\tau_{t}^{h} r_{t} h_{t}-g\right] \geq 0
$$

\subsection{Equilibrium}

For a given sequence of tax rates, a competitive equilibrium consists of individual policies and prices such that the individual policies solve the household's problem in (5) and (6), factor returns are given by equations in (2) and (3), the government budget constraint in (10) is satisfied, and the aggregate resource constraint

$$
c_{t}+k_{t+1}+h_{t+1}+g_{1}=f\left(k_{t}, n_{t}\right)+\left(1-\delta_{k}\right) k_{t}+\left(1-\delta_{h}\right) h_{t}
$$

is satisfied for all $t$.

\subsection{Optimal taxation}

The objective of the government is to maximize household welfare by announcing in period 1 a sequence of tax rates $\left\{\tau_{t}^{n}, \tau_{t}^{c}, \tau_{t+1}^{k}, \tau_{t+1}^{h}\right\}_{t=1}^{\infty}$. We assume that the government takes as given 
the first period tax rates on business capital income and the imputed rent, $\tau_{1}^{k}$ and $\tau_{1}^{h}$. As is always the case with capital taxation, we must impose some restriction on the government's ability to tax past investments. Otherwise, the government could trivially reach the first best allocation by confiscating part of the existing capital stocks.

\subsection{First best}

It is instructive to first consider the optimal tax structure when the government can use a full set of linear taxes. The first best solution is obtained by assuming that the government can directly choose the allocation (or dictate households' consumption, savings, and labor-leisure decisions). The first best allocations are determined by the following first-order conditions (together with transversality conditions):

$$
\begin{aligned}
u_{n_{t}}+u_{c_{t}} f_{n_{t}} & =0 \\
u_{c_{t}}-\beta u_{c_{t+1}}\left(1+r_{t+1}\right) & =0 \\
\beta u_{h_{t+1}}-u_{c_{t}}+\beta u_{c_{t+1}}\left(1-\delta_{h}\right) & =0 .
\end{aligned}
$$

Consider then the following tax rates for all $t \geq 1$ :

$$
\begin{aligned}
\tau_{t}^{c} & =-\tau_{t}^{n}=\tau \geq 0 \\
\tau_{t+1}^{k} & =0 \\
\tau_{t+1}^{h} & =\tau\left(1+\frac{\delta_{h}}{r_{t+1}}\right) .
\end{aligned}
$$

When the above tax rates are inserted into the household's first-order conditions in (7)-(9), the conditions become identical to the first-order conditions characterizing the first best allocation. Hence, if the tax policy in (12)-(14) is feasible, the resulting competitive equilibrium will correspond to the first best allocation. ${ }^{10}$

\footnotetext{
${ }^{10}$ It is straightforward to show that the tax policy determined by (12)-(14) is feasible if the value of initial assets in the economy is large enough relative to the present value of public spending.
} 
This result closely parallels Result 1 in Coleman (2000). Essentially, the first best solution is a form of a lump-sum tax. As a negative tax on labor income is a positive tax on leisure, the government can tax all goods and it need not distort household behavior. We note that the tax treatment of housing is similar to that of consumption in that they are both taxed at a positive rate whereas the tax rate on business capital income is zero. ${ }^{11}$

\section{Ramsey problems}

In this section, we lay out the Ramsey problem of the government and analyze optimal taxation under different restrictions on the government's ability to choose tax rates. An obvious problem with the first best tax scheme is that it requires subsidizing labor. Such a subsidy would give households an incentive to misrepresent hours of work. Therefore, we begin this section by analyzing the case where consumption can be taxed but labor may not be subsidized. We also impose the common constraint that the tax rate on business capital income may not exceed unity. This is a natural constraint because firms cannot be forced to operate capital for a certain loss. In contrast, there is no natural upper bound on the tax rate on the imputed rent, because there should always be some demand for housing. Hence, in this first case, which we consider as our benchmark case, we do not impose an upper bound on the tax rate on the imputed rent.

In addition to the benchmark case, it is interesting to see how the optimal tax treatment of housing depends on the consumption tax. Therefore, we solve the Ramsey problem also in the case where the consumption tax is fixed. This set-up encompasses the most standard case, where the government can tax only labor and capital. However, we maintain the assumption that labor may not be subsidized.

\footnotetext{
${ }^{11}$ In order to be consistent with the previous literature on housing taxation, we have assumed that depreciation of housing is tax deductible. Disallowing the deduction would simply scale the tax rate on the imputed rent downwards. In that case, the first best tax rates would be $\tau^{c}=\tau^{h}=-\tau^{n}=\tau>0$ and $\tau^{k}=0$.
} 
Finally, we consider two restrictions on the tax rate on the imputed rent: a maximum value for the tax rate on the imputed rent and a case where taxing housing is completely ruled out. The last case is useful in two respects. First, it reveals how ruling out housing taxation changes the optimal tax reform. Second, it allows us to evaluate the efficiency cost of not taxing housing by comparing the welfare gains from optimal tax reforms with and without the possibility to tax housing.

This section consists of three subsections. In the first subsection, we present the general methodology for solving the government problem in the benchmark case. In the second subsection, we analyze the case with the fixed consumption tax and in the last subsection we discuss the case where housing taxation is restricted.

\subsection{No tax on leisure}

The problem of the government is to choose the tax policy so as to maximize the utility of the representative household subject to the aggregate resource constraint, private sector's optimizing behavior, and the constraints imposed on the tax rates. Following the approach taken by Chamley (1986), Judd (1985), and others, we formulate the government's problem so that it directly chooses allocations. ${ }^{12}$

Let us first discuss the constraints to be imposed on the government's problem. Rewriting the budget constraint of the household in (6) by using the first-order conditions of the household gives

$$
\sum_{t=1}^{\infty} \beta^{t-1}\left(u_{c_{t}} c_{t}+u_{n_{t}} n_{t}+\beta u_{h_{t+1}} h_{t+1}-u_{c_{t}} \eta_{t} g_{2}\right)=u_{c_{1}} \eta_{1} A
$$

where $A=R_{1} k_{1}+R_{1}^{h} h_{1}$. (Recall that we defined above, for notational simplicity, $\eta_{t}=\frac{1}{1+\tau_{t}^{c}}$ )

\footnotetext{
${ }^{12}$ As shown in Lansing (1999) and discussed in Krusell (2002), in some cases, this approach leads to allocations that cannot be decentralized. This happens in the absence of anticipation effects, that is, when future tax rates do not affect the current decisions of the private sector. In our setting this kind of anticipation effects are always present even under logarithmic utility.
} 
This is the so-called implementability constraint. It states that the allocation chosen by the government must be compatible with individual optimization.

As mentioned above, we require all tax reforms to be such that $\tau_{t+1}^{k} \leq 1$ in all periods. This is equivalent to $R_{t+1} \geq 1$. Together with the household's first-order condition in (8), this constraint can be expressed as

$$
u_{c_{t}} \eta_{t}-\beta u_{c_{t+1}} \eta_{t+1} \geq 0
$$

In addition, the government is constrained to set a non-negative tax rate on labor income. Combining constraint $\tau_{t}^{n} \geq 0$ with the household's first-order condition in (7) gives

$$
u_{n_{t}}+u_{c_{t}} \eta_{t} f_{n_{t}} \geq 0
$$

As in Coleman (2000), the government then chooses consumption tax rates $\left\{\tau_{t}^{c}\right\}_{t=1}^{\infty}$ and allocations $\left\{c_{t}, n_{t}, k_{t+1}, h_{t+1}\right\}_{t=1}^{\infty}$ subject to the aggregate resource constraint, the implementability constraint, and the constraints on the tax rates. The Lagrangian for the government may be written as:

$$
\begin{aligned}
\mathcal{L}= & \sum_{t=1}^{\infty} \beta^{t-1} u\left(c_{t}, h_{t}, n_{t}\right) \\
& +\lambda\left[\sum_{t=1}^{\infty} \beta^{t-1}\left(u_{c_{t}} c_{t}+u_{n_{t}} n_{t}+\beta u_{h_{t+1}} h_{t+1}-u_{c_{t}} \eta_{t} g_{2}\right)-u_{c_{1}} \eta_{1} A\right] \\
& +\sum_{t=1}^{\infty} \beta^{t-1} \mu_{t}\left[f\left(k_{t}, n_{t}\right)+\left(1-\delta_{k}\right) k_{t}+\left(1-\delta_{h}\right) h_{t}-c_{t}-k_{t+1}-h_{t+1}-g_{1}\right] \\
& +\sum_{t=1}^{\infty} \beta^{t-1} \theta_{t}\left(u_{c_{t}} \eta_{t}-\beta u_{c_{t+1}} \eta_{t+1}\right) \\
& +\sum_{t=1}^{\infty} \beta^{t-1} \omega_{t}\left(u_{n_{t}}+u_{c_{t}} \eta_{t} f_{n_{t}}\right) .
\end{aligned}
$$

The first constraint is the implementability constraint. The second set of constraints contains an aggregate resource constraint for each period. The third and fourth sets of constraints are the restrictions on the tax rates. 
The first-order conditions for $n_{1}, c_{1}$ and $\eta_{1}$ can be written as:

$$
\begin{aligned}
n_{1} & : W n_{1}-\lambda u_{c_{1}} \eta_{1} \frac{\partial A_{1}}{\partial n_{1}}+\mu_{1} f_{n_{1}}+B_{0} u_{c n_{1}} \eta_{1}+\omega_{1}\left(u_{n n_{1}}+u_{c_{1}} \eta_{1} f_{n n_{1}}\right)=0 \\
c_{1} & : W c_{1}-\mu_{1}+\omega_{1} u_{n c_{1}}+B_{0} u_{c c_{1}} \eta_{1}=0 \\
\eta_{1}: & B_{0}=0
\end{aligned}
$$

where

$$
\begin{aligned}
W n_{1} & =u_{n_{1}}+\lambda\left(u_{n n_{1}} n_{1}+u_{n_{1}}+u_{c n_{1}} c_{1}\right) \\
W c_{1} & =u_{c_{1}}+\lambda\left(u_{c c_{1}} c_{1}+u_{c_{1}}+u_{n c_{1}} n_{1}\right) \\
B_{0} & =-\lambda A-\lambda g_{2}+\theta_{1}+\omega_{1} f_{n_{1}}
\end{aligned}
$$

Other first-order conditions are:

$$
\begin{aligned}
n_{t} & : W_{n_{t}}+\mu_{t} f_{n_{t}}+B_{t-1} u_{c n_{t}} \eta_{t}+\omega_{t}\left(u_{n n_{t}}+u_{c_{t}} \eta_{t} f_{n n_{t}}\right)=0 \\
c_{t} & : W_{c_{t}}-\mu_{t}+B_{t-1} u_{c c_{t}} \eta_{t}+\omega_{t} u_{n c_{t}}=0 \\
k_{t+1}: & -\mu_{t}+\beta \mu_{t+1}\left(1+r_{t+1}\right)+\beta \omega_{t+1} u_{c_{t+1}} \eta_{t+1} f_{n k_{t+1}}=0 \\
h_{t+1}: & : \beta W_{h_{t+1}}-\mu_{t}+\beta \mu_{t+1}\left(1-\delta_{h}\right)+\beta B_{t} u_{c h_{t+1}} \eta_{t+1}+\beta \omega_{t+1} u_{n h_{t+1}}=0 \\
\eta_{t}: & B_{t-1}=0,
\end{aligned}
$$

where

$$
\begin{aligned}
B_{t} & =-\lambda g_{2}+\theta_{t+1}-\theta_{t}+\omega_{t+1} f_{n_{t+1}} \\
W_{n_{t}} & =u_{n_{t}}+\lambda\left(u_{h n_{t}} h_{t}+u_{c n_{t}} c_{t}+u_{n n_{t}} n_{t}+u_{n_{t}}\right) \\
W_{c_{t}} & =u_{c_{t}}+\lambda\left(u_{h c_{t}} h_{t}+u_{c c_{t}} c_{t}+u_{c_{t}}+u_{n c_{t}} n_{t}\right) \\
W_{h_{t}} & =u_{h_{t}}+\lambda\left(u_{h h_{t}} h_{t}+u_{h_{t}}+u_{c h_{t}} c_{t}+u_{n h_{t}} n_{t}\right) .
\end{aligned}
$$

We also have the following Kuhn-Tucker conditions for all $t \geq 1$ :

$$
\begin{aligned}
\omega_{t}\left(u_{n_{t}}+u_{c_{t}} \eta_{t} f_{n_{t}}\right) & =0, \omega_{t} \geq 0, \text { and } u_{n_{t}}+u_{c_{t}} \eta_{t} f_{n_{t}} \geq 0 \\
\theta_{t}\left(u_{c_{t}} \eta_{t}-\beta u_{c_{t+1}} \eta_{t+1}\right) & =0, \theta_{t} \geq 0, \text { and } u_{c_{t}} \eta_{t}-\beta u_{c_{t+1}} \eta_{t+1} \geq 0
\end{aligned}
$$


The optimality conditions (19)-(25), the aggregate resource constraint (11), and the implementability constraint (15) determine the allocations $\left\{c_{t}, n_{t}, k_{t+1}, h_{t+1}\right\}_{t=1}^{\infty}$, the consumption tax rates $\left\{\tau_{t}^{c}\right\}_{t=1}^{\infty}$, and the multipliers $\lambda$ and $\left\{\omega_{t}, \theta_{t}\right\}_{t=1}^{\infty}$. After an optimal allocation has been found, prices $\left\{r_{t}, w_{t}\right\}_{t=1}^{\infty}$ are determined from equations (2) and (3). Finally, the tax rates on labor income, business capital income, and the imputed rent are solved from equations (7), (8), and (9), respectively.

Several interesting results may be obtained by inspecting the first-order conditions of the government Ramsey problem. Note first that if constraint (16) is not binding, first-order condition (23) becomes

$$
\lambda g_{2}=\omega_{t} f_{n_{t}}
$$

Since $\lambda>0$, this condition implies that if $g_{2}>0$ then $\omega_{t}>0$ for $t>1$. Therefore, whenever constraint (16) is not binding, the optimal tax system must involve $\tau^{n}=0 .{ }^{13}$

Consider then the optimal tax rate on business capital income. Denote the steady state value of $\mu_{t}$ by $\mu$, and similarly for other variables. Then, the steady state version of condition (21) can be written as

$$
1=\beta(1+r)+\frac{\beta \omega u_{c} \eta f_{n k}}{\mu} .
$$

The steady state version of the household first-order condition (8) in turn becomes

$$
1=\beta\left(1+\left(1-\tau^{k}\right) r\right)
$$

By combining these two conditions we obtain

$$
\tau^{k}=-\frac{\omega u_{c} \eta f_{n k}}{r \mu}
$$

Since $\omega>0$, it follows that the long run tax rate on business capital income is negative.

\footnotetext{
${ }^{13}$ If $g_{2}=0$, condition (26) implies that $\omega_{t}=0$. That is, the government first-order condition (23) is satisfied for all allocations and consumption tax rates. Therefore, in the absence of transfers, there need not be a unique path of optimal tax rates. This point is also discussed in Coleman (2000).
} 
The government first-order conditions for consumption and housing are complicated enough not to allow drawing any general conclusions. This is because, in general, the signs of $W_{c}, W_{h}$, and $W_{n}$ depend on the magnitude of $\lambda$, the multiplier of the implementability constraint. However, we can characterize these tax rates assuming logarithmic utility function, as in (4). ${ }^{14}$ Consider first the tax rate on consumption. Combining (20)-(22) gives

$$
u_{n}+u_{c} f_{n}=-\lambda\left(u_{n n} n+u_{n}\right)-\omega\left(u_{n n}+u_{c} \eta f_{n n}\right)
$$

where the right hand side is strictly positive. The household first-order condition (7) in turn implies that

$$
\left(1+\tau^{c}\right) u_{n}+u_{c} f_{n}=0
$$

Because $u_{n}<0$, combining these two conditions shows that $\tau^{c}>0$.

Finally, using equations (20), (21) and (23), we can write the steady state version of first-order condition (22) as

$$
\frac{u_{h}}{u_{c}}-\left(\delta_{h}+r\right)=\omega \eta f_{n k} .
$$

The first-order conditions of the household (8) and (9) in turn may be rewritten as

$$
\frac{u_{h}}{u_{c}}=\eta\left(R-R^{h}\right)
$$

Combining the above equations results in

$$
\tau^{h}-\tau^{k}=\frac{\omega f_{n k}}{r}+\tau^{c}\left(1+\frac{\delta_{h}}{r}\right)
$$

By collecting these results, we obtain

Result 1 If the government cannot subsidize labor and households receive transfers, in a steady state

i) the tax rate on labor income is zero.

\footnotetext{
${ }^{14}$ This implies $W_{n_{t}}=u_{n_{t}}+\lambda\left(u_{n n_{t}} n_{t}+u_{n_{t}}\right), W_{c_{t}}=u_{c_{t}}$, and $W_{h_{t}}=u_{h_{t}}$.
} 
ii) the tax rate on business capital income is negative.

iii) if the utility function is logarithmic, the tax rate on consumption is strictly positive and the tax rate on the imputed rent is higher than the tax rate on business capital income.

The first two results are the same as in Coleman (2000). The tax rate on labor income should be zero because the consumption tax rate is more efficient; by taxing consumption the government is able to tax transfers. In addition, given that labor is not taxed it is beneficial to subsidize business capital accumulation. This is because increased business capital accumulation increases the marginal productivity of labor. This in turn reduces the cost of not being able to subsidize labor.

The optimal tax treatment of housing depends both on how consumption is taxed and how other forms of saving are taxed. When the utility function is logarithmic, the long run tax rate on the imputed rent should be higher than the tax rate on business capital income. However, it is not possible to determine analytically whether the long run tax rate on the imputed rent should be positive or negative. This seems natural since housing is both a consumption good and a form of savings, and consumption is taxed at a strictly positive rate while savings are subsidized.

\subsection{A fixed consumption tax rate}

In the previous literature on housing taxation, consumption taxation is typically entirely ignored. In order to examine the importance of allowing for optimally set consumption taxes, we now consider a case where the tax rate on consumption is required to remain fixed at a certain predetermined level, $\bar{\tau}^{c} \geq 0$.

The problem of the government now looks very similar to the one above except that now we do not have the first-order conditions related to the consumption tax rate in (23). This directly implies that it is no longer possible to determine analytically whether labor income 
should be taxed or not. That is, we cannot infer whether the non-negativity constraint on the labor income tax rate is binding or not.

The case where $\omega>0$ is quite cumbersome and not very insightful. Also, our numerical analysis shows that for small values of $\bar{\tau}^{c}$ labor income should be taxed. We will therefore discuss here only the case where $\omega=0$. In that case, it directly follows from equation (27) that $\tau^{k}=0$. Again determining the tax rate on housing is more complicated. ${ }^{15}$ However, under logarithmic utility, combining (20)-(22) gives

$$
\frac{u_{h_{t+1}}}{u_{c_{t+1}}}-\left(\delta_{h}+r_{t+1}\right)=\frac{-\lambda g_{2} \bar{\eta} u_{c c_{t+1}}\left(\delta_{h}+r_{t+1}\right)}{u_{c_{t+1}}},
$$

where $\bar{\eta}=\frac{1}{1+\bar{\tau}^{c}}$. Combining this with the first-order condition of the household

$$
\frac{u_{h_{t+1}}}{u_{c_{t+1}}}=\bar{\eta}\left(R_{t+1}-R_{t+1}^{h}\right)
$$

gives

$$
\tau_{t+1}^{h} r_{t+1}-\tau_{t+1}^{k} r_{t+1}-\bar{\tau}^{c}\left(\delta_{h}+r_{t+1}\right)=\frac{-\lambda g_{2} u_{c c_{t+1}}\left(\delta_{h}+r_{t+1}\right)}{u_{c_{t+1}}} .
$$

Inspection of equation (31) reveals that if $\bar{\tau}^{c}=0$, the tax rate on imputed rent should be higher than business capital income tax rate in all periods if $g_{2}>0$.

By collecting these results, we obtain

Result 2 With a fixed consumption tax, it may be optimal to tax labor income. If that is the case

i) the long run tax rate on business capital income is zero.

ii) if the utility function is logarithmic, the long run tax rate on the imputed rent is given by

$$
\tau^{h}-\bar{\tau}^{c}\left(1+\frac{\delta_{h}}{r}\right)=\frac{\lambda g_{2}}{c}\left(1+\frac{\delta_{h}}{r}\right)>0 .
$$

\footnotetext{
${ }^{15}$ When $\omega=0$ and $\theta=0$, we have $W c_{t}=\mu_{t}+\lambda g_{2} u_{c c_{t}} \eta_{t}$. Hence, even if $\omega=0$ and $\theta=0$, it is not possible to pin down the sign of $W c_{t}$.
} 
iii) if the utility function is logarithmic and $g_{2}=0$, and $\bar{\tau}^{c}=0$ then $\tau_{t}^{h}=\tau_{t}^{k}$ in all periods and both are zero in the long run.

Thus, in general, the tax treatment of housing should depend on how high the consumption tax is and on the amount of transfers that households receive. The intuition for this result follows from the consumption role of housing. If households receive lump-sum transfers, the tax on the imputed rent can be used to tax part of them. On the other hand, even in the absence of transfers, if other consumption is taxed, housing should also be taxed so as not to distort the relative prices of consumption goods and housing. However, in the special case where there are no transfers and the consumption tax is fixed at zero, the tax treatment of housing should be no different from that of business capital income. This reflects the asset role of housing. In particular, in the short run, taxing housing is a way of taxing part of the initial assets.

\subsection{Restrictions on the tax rate on the imputed rent}

In this subsection, we analyze a situation where the tax rate on the imputed rent cannot exceed a given upper bound, $\bar{\tau}^{h}$. We again assume that the consumption tax rate is optimally chosen. ${ }^{16}$ This restriction implies that

$$
R_{t+1}^{h} \geq 1-\delta_{h}-\bar{\tau}^{h} r_{t+1}
$$

This inequality, together with the household's first-order condition (9), means that the government is constrained to choose allocations that satisfy

$$
u_{c_{t}} \eta_{t} \geq \beta u_{c_{t+1}} \eta_{t+1}\left(1-\delta_{h}-\bar{\tau}^{h} r_{t+1}\right)+\beta u_{h_{t+1}} .
$$

Two cases are of special interest for us: First, the optimal tax system considered in the previous subsections may involve very high tax rates on the imputed rent during the

\footnotetext{
${ }^{16}$ Since the consumption tax rate is optimally chosen, we assume here that the household receives tranfers, i.e. $g_{2}$ is strictly positive.
} 
transition. Here, we wish to examine how the transition is changed if we restrict the tax treatment in the same manner as we restrict the tax treatment of business capital income, i.e. set $\bar{\tau}^{h}=1$. As long as this constraint is not binding in the steady state, the characterization of the steady state tax rates remains the same as in Result 2.

Second, we want to analyze the transition under the assumption that housing cannot be taxed at all, i.e. $\bar{\tau}^{h}=0$. Here an important element of the analysis is the observation that simply ignoring housing taxation leads to an allocation which cannot be decentralized using the remaining tax instruments. The constraint (32) must be imposed separately on the government and it will always be binding. Therefore, letting $\gamma$ be the multiplier on (32), we have $\gamma_{t}>0$ for all $t$.

The assumption that housing may not be taxed changes the results in two ways compared to the benchmark case in section 3.1. First, now the government's first-order condition (23) becomes

$$
-\lambda g_{2}+\theta_{t+1}-\theta_{t}+\gamma_{t+1}-\gamma_{t}\left(1-\delta_{h}\right)+\omega_{t+1} f_{n_{t+1}}=0
$$

Consider a situation where $\theta=0$. Since $\gamma_{t}>0$ is always strictly positive, it may now be that $\omega=0$ even if the consumption tax rate is optimally chosen. That is, if housing cannot be taxed, it may become optimal to tax labor income. If this is the case, from condition (27) it directly follows that $\tau^{k}=0$ in the long run. In addition, following the same procedure as in (28) and (29), we can determine that under logarithmic utility $\tau^{c}>0$.

Collecting these results gives:

Result 3 When housing cannot be taxed, it may be optimal to tax labor income. If that is the case

i) the long run tax rate on business capital income is zero.

ii) if the utility function is logarithmic, consumption should always be taxed.

When housing cannot be taxed, the optimal tax system may feature taxing both consumption and labor income while the optimal long run business capital tax rate is zero. This 
tax structure is very different from the one in section 3.1 where labor income is not taxed and business capital income is subsidized.

In general, the results in this section show that the optimal tax treatment of housing depends on the tax treatment of both consumption and business capital income. Broadly speaking, we have two different situations: If it is optimal to tax labor income, the tax rate on business capital income should be zero in the long run. ${ }^{17}$ When this is the case, housing should be taxed whenever consumption is taxed. If, on the other hand, it is not optimal to tax labor income, business capital income should subsidized. Again, the tax rate on imputed rent should be higher than the tax rate on business capital income, but it is not possible to determine whether the tax rate on imputed rent should be positive or not.

\section{Quantitative analysis}

In this section, we present our numerical results. We find the solution to the Ramsey problems by solving the system of non-linear equations formed by the government first-order conditions, the implementability constraint, the aggregate resource constraints, and the Kuhn-Tucker constraints using broydn's algorithm.

We begin this section by explaining the calibration of the model. We then present the optimal tax reforms and the corresponding welfare effects in the different cases discussed in the previous section. In the last subsection, we experiment with different parameter values to test the robustness of the results.

\footnotetext{
${ }^{17}$ This is the well known Chamley-Judd result. Of course, there is a large literature analyzing different justifications for non-zero long run tax rates on the business capital income. For references see e.g. Lansing (1999).
} 


\subsection{Calibration}

We calibrate the model to the US economy. The production function is Cobb-Douglas with capital share $\alpha$. Greenwood et al. (1995) have estimated the share of business capital in the production function when total capital stock is disaggregated into housing and business capital. Based on their estimate, we set $\alpha=0.29$. The depreciation rates of business capital and housing are set at $\delta_{k}=0.1$ and $\delta_{h}=0.05$. The National Income and Product Accounts suggest an annual depreciation rate for housing capital around 0.015. By choosing a higher depreciation rate, we want to take maintenance costs into account.

Based on Carey and Rabesona (2004), we assume that in the initial tax system $\tau^{n}=0.23$, and $\tau^{c}=0.07$. The estimates for the effective tax rates on capital vary a lot. We assume that $\tau^{h}=0$ and $\tau^{k}=0.5$. These rates are within the range of empirical estimates in the literature. $^{18}$ These initial tax rates imply a government revenue-to-total output ratio of 0.213.

We employ the logarithmic utility function in (4). Parameters $\beta, \alpha^{c}, \alpha^{h}, g_{1}$, and $g_{2}$ are chosen so as to match the following aggregate targets. 1) Business capital-to-housing ratio $k / h=1$. 2) Total capital-to-total output ratio $(k+h) / y=3.13$, where $y=k^{\alpha} n^{1-\alpha}+$ $\left.\left(r+\delta_{h}\right) h .3\right)$ Transfers-to-total government spending ratio $g_{2} /\left(g_{1}+g_{2}\right)=0.43$. 4) Labor supply $n=0.333$. 5) The government budget is balanced and there is no government debt.

The first two of these targets are based on the National Income and Product Accounts (NIPA). The Fixed Asset Table in NIPA contains private residential and non-residential assets. We interpret all business capital in the model as private non-residential assets and all housing capital in the model as private residential assets. The third target is from the 2004 Economic Report of the President. ${ }^{19}$ The fourth target implies that households spend

\footnotetext{
${ }^{18}$ For the tax rate on the imputed rent, see Fullerton (1987). In a similar model, Greenwood et al. (1995) set the tax rate on business capital equal to 0.70, arguing that it includes not just taxes but also various regulatory costs.

${ }^{19}$ We use Table B-83 to first calculate the sum of government consumption expenditures and transfer payments. We then calculate the average share of transfer payments of this sum for years 1999-2003.
} 
one third of their time working. The last constraint pins down the sum of $g_{1}$ and $g_{2}$. All parameter values are collected in table 1 .

\section{Table 1: Parameter values.}

\begin{tabular}{lcc}
\hline \hline Preferences & $\beta$ & 0.9733 \\
& $\alpha^{c}$ & 0.3312 \\
& $\alpha^{h}$ & 0.0782 \\
Technology & $\alpha$ & 0.29 \\
& $\delta_{k}$ & 0.1 \\
& $\delta_{h}$ & 0.05 \\
Tax system & $\tau^{n}$ & 0.23 \\
& $\tau^{h}$ & 0 \\
& $\tau^{c}$ & 0.07 \\
& $\tau^{k}$ & 0.50 \\
Government expenditures & $g_{1}$ & 0.0625 \\
& $g_{2}$ & 0.0471 \\
\hline
\end{tabular}

\subsection{Optimal tax reforms}

We first present the transitional dynamics of the economy in the benchmark case. Figure 1 shows the paths of the optimal tax rates. The tax rate on labor income, being zero from period 1 onwards, is not shown in the figure. 
Figure 1: Optimal tax rates when $\tau^{n} \geq 0$ and $\tau^{k} \leq 1$
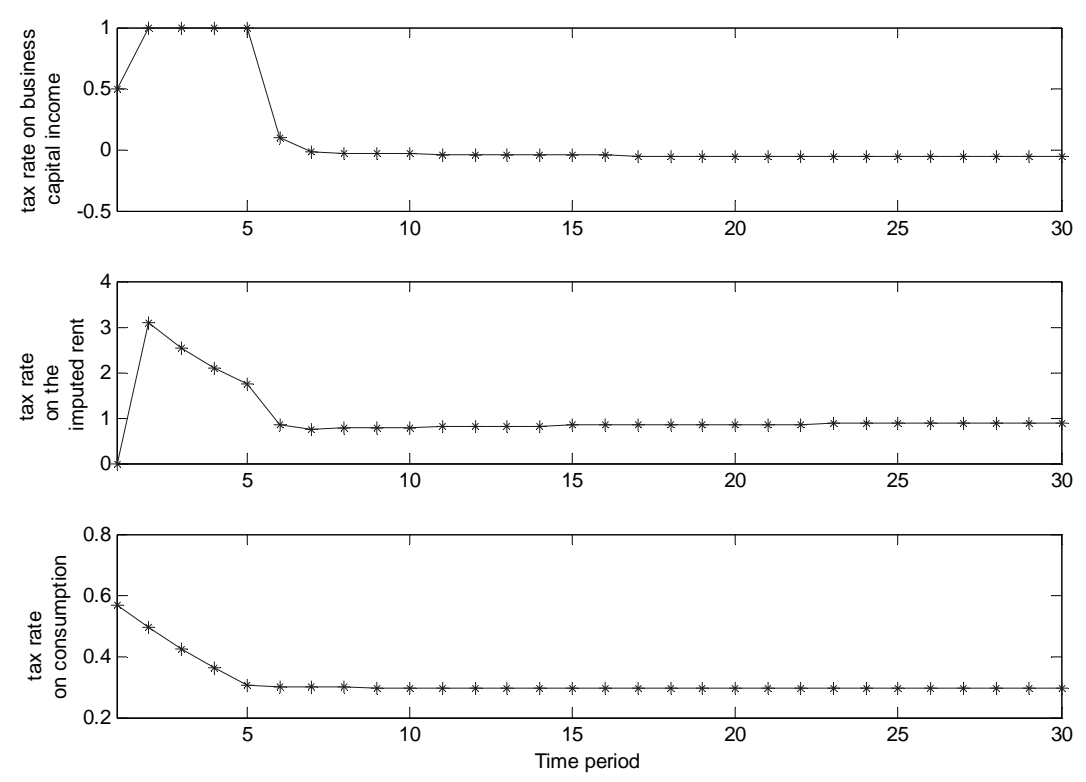

Recall that we require the period 1 tax rates on business capital income and the imputed rent to remain fixed. In addition, the tax rate on business capital income is required not to exceed one during the transition. This constraint is binding in periods $2-5$. The tax rate on the imputed rent is remarkably high during the first periods of the transition. The tax rate on consumption increases immediately after the reform. All tax rates converge close to their new steady state levels in less than ten periods. 
Figure 2 below shows the corresponding transitionary dynamics of business and housing capital stocks and labor supply.

Figure 2: Transition paths when $\tau^{n} \geq 0$ and $\tau^{k} \leq 1$.
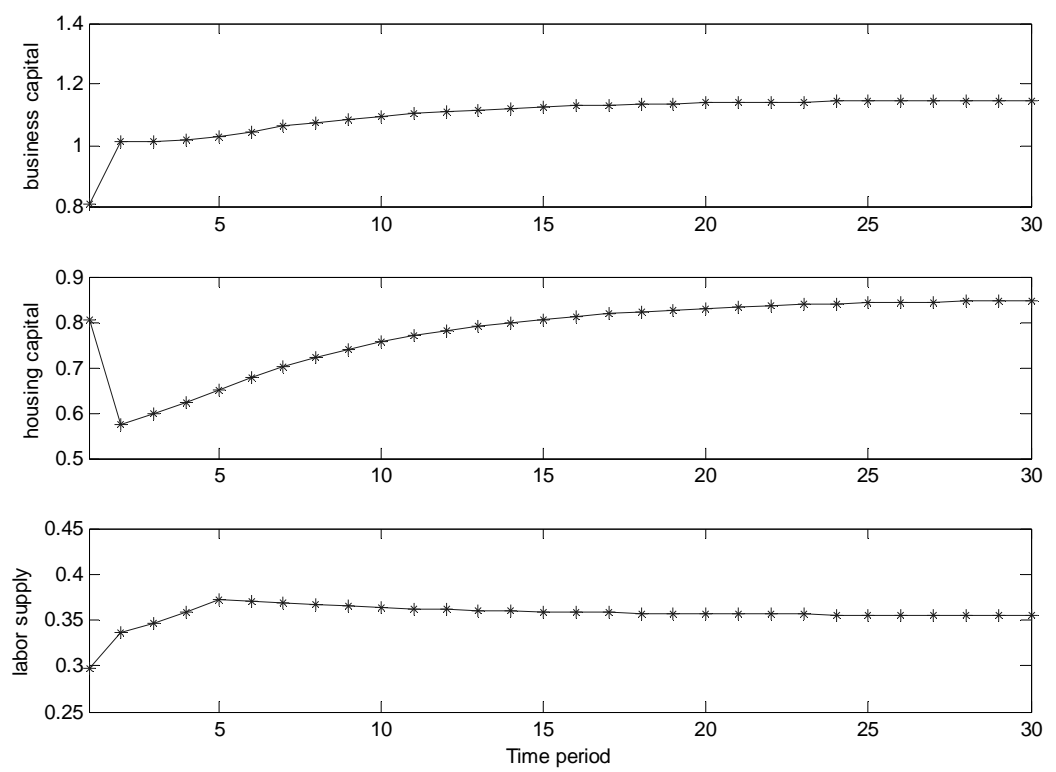

The business capital stock increases steadily during the transition towards its post-reform steady state level which is substantially higher than in the initial steady state. The housing capital stock first decreases after which it increases towards the new steady state level which is also somewhat higher than the initial steady state level. The labor supply first increases above its new steady state level which is above the initial steady state level.

Table 2 below shows the optimal tax rates in the different cases discussed above in the short and long run. The first four rows present the benchmark case where we restrict the labor income tax rate to be non-negative and the business capital income tax rate to be at most one. The other three cases present different additional constraints on the tax instruments. 
Table 2: Optimal tax rates.

\begin{tabular}{lccccccc}
\hline \hline \multirow{2}{*}{ Constraints on tax policy } & & \multicolumn{5}{c}{ Tax rate paths } \\
& & year 1 & year 2 & year 3 & year 10 & year 20 & year $\infty$ \\
\hline Case 1: & $\tau^{k}$ & 0.50 & 1.00 & 1.00 & -0.04 & -0.06 & -0.06 \\
$\tau^{n} \geq 0$ and $\tau^{k} \leq 1$ & $\tau^{h}$ & 0.00 & 3.09 & 2.54 & 0.79 & 0.85 & 0.87 \\
& $\tau^{c}$ & 0.57 & 0.49 & 0.43 & 0.30 & 0.29 & 0.29 \\
& $\tau^{n}$ & 0.00 & 0.00 & 0.00 & 0.00 & 0.00 & 0.00 \\
\hline Case 2: & $\tau^{k}$ & 0.50 & 0.80 & 0.58 & -0.04 & -0.06 & -0.06 \\
$\tau^{n} \geq 0, \tau^{k} \leq 1$ & $\tau^{h}$ & 0.00 & 1.00 & 1.00 & 0.82 & 0.90 & 0.93 \\
and $\tau^{h} \leq 1$ & $\tau^{c}$ & 0.48 & 0.42 & 0.39 & 0.31 & 0.31 & 0.31 \\
& $\tau^{n}$ & 0.00 & 0.00 & 0.00 & 0.00 & 0.00 & 0.00 \\
\hline Case 3: & $\tau^{k}$ & 0.50 & 1.00 & 1.00 & 0.19 & 0.01 & 0.00 \\
$\tau^{n} \geq 0, \tau^{k} \leq 1$ & $\tau^{h}$ & 0.50 & 1.00 & 1.00 & 0.49 & 0.34 & 0.35 \\
$\tau^{h} \leq 1$ and $\tau^{c}=0.07$ & $\tau^{n}$ & 0.02 & 0.01 & 0.05 & 0.24 & 0.24 & 0.24 \\
\hline Case 4: & $\tau^{k}$ & 0.50 & 0.22 & 0.20 & 0.12 & 0.06 & 0.00 \\
$\tau^{n} \geq 0, \tau^{k} \leq 1$ & $\tau^{c}$ & 0.43 & 0.41 & 0.40 & 0.34 & 0.31 & 0.27 \\
$\tau^{h}=0$ & $\tau^{n}$ & 0.04 & 0.03 & 0.03 & 0.07 & 0.09 & 0.12 \\
\hline
\end{tabular}

Considering the optimal tax structure in the different cases of table 2 reveals several important insights about the optimal tax treatment of the imputed rent. Consider first the benchmark case (case 1 in the table). In the short run, the optimal tax rates on the imputed rent and business capital income are both very high. This reflects the attempt to tax initial capital stocks. In the long run, the optimal tax rate on the imputed rent remains high (0.87), whereas the tax rate on business capital income is slightly below zero $(-0.06) .{ }^{20}$ The tax rate on consumption falls from 0.57 in the first period to a long run value of 0.29 . Hence, in the long run, both housing and consumption are taxed at relatively high rates, whereas business capital is subsidized.

\footnotetext{
${ }^{20}$ Recall, however, that we assume that housing depreciation is deducted from the imputed rent.
} 
The constraints imposed on the tax rates on business capital income and the imputed rent influence always both of these tax rates. In the benchmark case, the constraint $\tau^{k} \leq 1$ is binding during the first periods of the transition. However, an upper bound on the tax rate on the imputed rent (case 2), not only leads to a lower tax rate on the imputed rent but also to a lower tax rate on business capital income. Interestingly, the constraint $\tau^{k} \leq 1$ is then never binding.

Comparing case 3 with case 1 , shows that the optimal tax treatment of housing is very sensitive to whether or not we can freely tax consumption. The optimal long run tax rate on the imputed rent falls from 0.87 in the benchmark case to 0.35 when the consumption tax is fixed at its initial level which is lower than the optimal level. In this case, it is also optimal to tax labor. As a result, the long run tax rate on business capital income is then zero (see Result 2).

Ruling out housing taxation altogether (case 4) changes the steady state tax structure in a similar way as fixing the consumption tax. That is, it now becomes optimal to tax labor income and the long run tax rate on business capital income is zero (see Result 3).

Interestingly, ruling out housing taxation also changes the dynamics of the optimal business capital taxation substantially. In case 4 , the tax rate on business capital income starts to diminish from the very first period after the reform is announced. In addition, it now converges to zero very slowly. After 20 periods, the optimal tax rate on business capital income is still at $0.06 .{ }^{21}$ In other words, if housing cannot be taxed, the tax rate on business capital income does not feature the usual dynamics with very high tax rates in the first periods and a rapid convergence to the new steady state tax rate. This is due to the fact that households have two savings vehicles, housing and business capital. Hence, ruling out housing taxation diminishes the government's ability to tax the initial business capital stock as well.

\footnotetext{
${ }^{21}$ In fact, it appears to converge to zero only asymptotically.
} 


\subsection{Welfare gains}

Our welfare measure is the 'equivalent consumption variation'. It tells how much consumption should be increased in the initial steady state so as to make the household indifferent between the status quo and the tax reform when leisure and housing choices are kept fixed. ${ }^{22}$ The overall welfare gain in table 3 takes household welfare during the transition periods into account. The steady state gain compares welfare in the initial steady state to the welfare in the new steady state.

Table 3: Welfare effects of the tax reforms.

\begin{tabular}{lcc}
\hline \hline Tax reform & Overall welfare gain & Steady state gain \\
\hline$\tau^{n} \geq 0$ and $\tau^{k} \leq 1$ & $3.5 \%$ & $7.9 \%$ \\
$\tau^{n} \geq 0, \tau^{k} \leq 1$ and $\tau^{h} \leq 1$ & $3.4 \%$ & $7.5 \%$ \\
$\tau^{c}=0.07, \tau^{n} \geq 0, \tau^{k} \leq 1$ and $\tau^{h} \leq 1$ & $2.1 \%$ & $4.2 \%$ \\
$\tau^{h}=0, \tau^{n} \geq 0$, and $\tau^{k} \leq 1$ & $2.0 \%$ & $7.2 \%$ \\
\hline
\end{tabular}

These welfare results suggest several conclusions. The ability to tax the return to housing at a very high rate (exceeding 100\%) is not important. Imposing an upper bound of unity to the tax rate on the imputed rent decreases the overall welfare gain only by one tenth of a percentage point. This is despite the fact that the optimal tax rate on the imputed rent is indeed quite high during the first periods after the reform in the benchmark case. In contrast, the ability to tax consumption is important. The overall welfare gain of the tax reform falls substantially if the consumption tax is fixed at its initial, relatively low level.

The last row presents the welfare gain when housing is not taxed at all. Our preferred measure for the welfare cost of not taxing housing is the difference between the overall welfare gains in the first and the last row. The overall welfare gain is 1.5 percentage points lower than in the benchmark case where only labor subsidies and confiscatorily high business capital

\footnotetext{
${ }^{22}$ Of course, the required compensation would be smaller if households were allowed to reoptimize after receiving the compensation.
} 
income tax rates are excluded. This is about $43 \%$ of the welfare gain in the benchmark case. In this sense, the welfare cost of not taxing housing is very high.

The steady state effects are always much larger than the overall welfare effect. The postreform steady state is associated with a higher stock of capital which is built up by a high saving rate during the transition. The welfare cost of not taxing housing appears much smaller when we compare only steady state welfare. Hence, the welfare cost of not taxing housing is largely related to the transitionary dynamics.

\subsection{Sensitivity analysis}

In this section, we experiment with different assumptions about the elasticity of substitution between consumption, housing, and leisure. In doing so, we focus on the benchmark case where labor may not be subsidized and the tax rate on business capital income may not exceed one.

Following Greenwood and Hercowitz (1991), we define the following 'home production function':

$$
c^{*}(h, n)=\left(\theta^{h} h^{\gamma^{h}}+\left(1-\theta^{h}\right)(1-n)^{\gamma^{h}}\right)^{1 / \gamma^{h}}
$$

where $0<\theta^{h}<1$ is the weight of housing in the home production function. The elasticity of substitution between housing and leisure is given by $\varepsilon^{h}=\frac{1}{1-\gamma^{h}}$ with $\gamma^{h}<1$ and $\gamma^{h} \neq 0$. The utility function is then given by

$$
\begin{aligned}
& u(c, h, n)=\frac{\left[\left(\theta^{c} c^{\gamma^{c}}+\left(1-\theta^{c}\right) c^{* \gamma^{c}}\right)^{1 / \gamma^{c}}\right]^{1-\sigma}}{1-\sigma}, \text { for } \sigma>0, \sigma \neq 1 \\
& u(c, h, n)=\log \left(\theta^{c} c^{\gamma^{c}}+\left(1-\theta^{c}\right) c^{* \gamma^{c}}\right)^{1 / \gamma^{c}}, \text { for } \sigma=1
\end{aligned}
$$

where $0<\theta^{c}<1$ is the utility weight of consumption and $\sigma$ is the inverse of the intertemporal elasticity of substitution. The elasticity of substitution between 'home production' and consumption is given by $\varepsilon^{c}=\frac{1}{1-\gamma^{c}}$ with $\gamma^{c}<1$ and $\gamma^{c} \neq 0$. 
We will set $\sigma=1$ and consider values $1 / 2$ and 2 for both $\varepsilon^{c}$ and $\varepsilon^{h} .^{23}$ In all cases, we calibrate the other preference parameters so as to match the same targets as in section 5.1 with the same initial tax system and the same market technology parameters.

The logarithmic utility function employed in section 5.1 is a special case of the utility function considered here with $\varepsilon^{c}=1$ and $\varepsilon^{h}=1$. So as to facilitate comparison of the different cases, we also report here the steady state tax rates under the logarithmic utility. The results on the optimal steady state tax rates are summarized in table 4.

Table 4. Optimal steady state tax rates under different $\varepsilon^{c}$ and $\varepsilon^{h}$.

\begin{tabular}{|c|c|c|c|c|c|c|}
\hline & \multicolumn{6}{|c|}{ Steady state tax rates } \\
\hline & \multicolumn{3}{|c|}{$\varepsilon^{c}=1$} & \multicolumn{3}{|c|}{$\varepsilon^{h}=1$} \\
\hline & $\varepsilon^{h}=1 / 2$ & $\varepsilon^{h}=1$ & $\varepsilon^{h}=2$ & $\varepsilon^{c}=1 / 2$ & $\varepsilon^{c}=1$ & $\varepsilon^{c}=2$ \\
\hline$\tau^{k}$ & -0.05 & -0.06 & -0.06 & -0.05 & -0.06 & -0.06 \\
\hline$\tau^{h}$ & 1.13 & 0.87 & 0.70 & 0.63 & 0.87 & 1.00 \\
\hline$\tau^{c}$ & 0.27 & 0.29 & 0.30 & 0.32 & 0.29 & 0.25 \\
\hline$\tau^{n}$ & 0 & 0 & 0 & 0 & 0 & 0 \\
\hline
\end{tabular}

The variation in the degree of substitutability between leisure and housing or between home production and consumption has virtually no effect on the optimal tax rate on business capital income. Also the labor income tax rate remains unaffected as the non-negativity constraint binds in all cases.

In contrast, the long run tax rate on the imputed rent is quite sensitive not only to the substitutability between leisure and housing but also the substitutability between consumption and home production. As the elasticity of substitution between housing and leisure, $\varepsilon^{h}$, increases from $1 / 2$ to 2 , the long run tax rate on the imputed rent decreases from 1.13 to 0.70 . When the elasticity of substitution between consumption and home production, $\varepsilon^{c}$ increases from $1 / 2$ to 2 , the optimal tax rate on the imputed rent increases from 0.63 to 1.00 .

\footnotetext{
${ }^{23}$ We found that different reasonable values for $\sigma$ did not change the results on the optimal long run tax rates substantially.
} 
Variations in these elasticities have a more modest effect on the optimal tax rate on consumption. Changes in $\varepsilon^{h}$ leave the optimal consumption tax rate almost unaffected while an increase in $\varepsilon^{c}$ from $1 / 2$ to 2 , decreases the optimal consumption tax rate from 0.32 to 0.25 .

Table 5 shows the overall welfare gain from optimal tax reforms with and without the possibility to tax housing. Again, we measure the welfare cost of not taxing housing as the difference between these two welfare gains. The upper part reports the results related to changes in the elasticity of substitution between housing and leisure when $\varepsilon^{c}=1$ while the bottom of the table shows the same results for different elasticities between home production and consumption keeping the substitutability between housing and leisure fixed at $\varepsilon^{h}=1$.

Table 5: Welfare effects under different $\varepsilon^{c}$ and $\varepsilon^{h}$.

\begin{tabular}{lccc}
\hline \hline Elasticity of substitution & \multicolumn{2}{c}{ Tax reform } \\
\hline & & $\tau^{n} \geq 0$ and $\tau^{k} \leq 1$ & $\tau^{h}=0, \tau^{n} \geq 0$ and $\tau^{k} \leq 1$ \\
\hline \multirow{3}{*}{$\varepsilon^{c}=1$} & $\varepsilon^{h}=1 / 2$ & $3.6 \%$ & $1.5 \%$ \\
& $\varepsilon^{h}=2$ & $3.5 \%$ & $2.0 \%$ \\
& $\varepsilon^{h}=1 / 2$ & $2.3 \%$ & $3.0 \%$ \\
$\varepsilon^{h}=1$ & $\varepsilon^{c}=1$ & $3.5 \%$ & $1.9 \%$ \\
& $\varepsilon^{c}=2$ & $7.0 \%$ & $2.0 \%$ \\
\hline
\end{tabular}

The overall welfare gain of moving to an optimal tax system, with the possibility to tax housing, is not very sensitive to the elasticity of substitution between housing and leisure but it increases rapidly with the elasticity of substitution between consumption and home production.

The welfare cost of not taxing housing decreases with the elasticity of substitution between housing and leisure. With $\varepsilon^{h}=1 / 2$ (and $\varepsilon^{c}=1$ ), the cost is $2.1 \%$ in terms of consumption, which is $58 \%$ of the welfare gain when housing can be taxed. With $\varepsilon^{h}=2$, the cost is just 
$0.9 \%$ in terms of compensation or $23 \%$ of the welfare gain. Intuitively, when this elasticity is low, it is efficient to tax housing heavily. The welfare cost of not being able to tax housing is then high.

The welfare cost of not taxing housing increases with the elasticity of substitution between consumption. With $\varepsilon^{c}=1 / 2\left(\right.$ and $\left.\varepsilon^{h}=1\right)$ the cost is $0.4 \%$ in terms of consumption, which is $17 \%$ of the welfare gain when housing can be taxed. With $\varepsilon^{c}=2$, the cost is $4.8 \%$ in terms of compensation or $69 \%$ of the welfare gain.

\section{Conclusions}

We have considered the optimal tax status of housing within a dynamic general equilibrium model. In the short run, the optimal tax treatment of housing resembles that of business capital: both should be taxed heavily during the first periods of an optimal tax reform. However, the optimal long run tax rate on the imputed rent is very sensitive to whether or not consumption can also be taxed. If consumption is taxed at a high rate, as is the case in many European economies, then housing should be taxed at a relatively high rate as well. Hence, the tax treatment of housing should be compared not just to the tax treatment of business capital, as is usually done, but also to the tax treatment of consumption.

We also found that ruling out housing taxation altogether changes the optimal tax treatment of business capital substantially. In particular, if the government cannot tax housing at all, it should not try to tax initial assets by taxing business capital income at high rates during the first periods of the tax reform.

\section{References}

Atkeson, Andrew, V.V. Chari, and Patrick J. Kehoe (1999), Taxing Capital Income: A Bad Idea, Federal Reserve Bank of Minneapolis Review 23(3), 3-17. 
Baxter, Marianne and Urban J. Jerman (1999), Household Production and the Excess Sensitivity of Consumption to Current Income, American Economic Review 89(4), 902-920.

Berkovec, James and Don Fullerton (1992), A General Equilibrium Model of Housing, Taxes, and Portfolio Choice, Journal of Political Economy 100(2), 390-429.

Bye, Brita and Turid Åvitsland (2003), The welfare effects of housing taxation in a distorted economy: a general equilibrium analysis, Economic Modelling 20, 895-921.

Carey, David and Josette Rabesona (2004), Tax Ratios on Labor and Capital Income and on Consumption, in Sorensen, Peter Birch (ed.) Measuring the Tax Burden on Capital and Labor, The MIT Press, Cambridge, Massachusetts.

Chamley, Christophe (1986), Optimal taxation capital income in general equilibrium with infinite lives, Econometrica 54, 607-22.

Coleman II, Wilbur John (2000), Welfare and optimum dynamic taxation of consumption and income, Journal of Public Economics 76, 1-39.

Cremer, Helmuth and Firouz Gahvari (1998), On Optimal Taxation of Housing, Journal of Urban Economics 43, 315-335.

Eerola, Essi and Niku Määttänen (2006), On the Political Economy of Housing's Tax Status, The B.E. Journal of Macroeconomics 6(2) (Topics), Article 7.

Englund, Peter (2003), Taxing Residential Housing Capital, Urban Studies, 40(5-6), 937-952. Fullerton, Don (1987), The Indexation of Interest, Depreciation, and Capital Gains and Tax Reform in the United States, Journal of Public Economics 32(1), 25-52.

Gahvari, Firouz (1984), Incidence and efficiency aspects of differential taxation of residential and industrial capital in a growing economy, Journal of Public Economics 25, 211-233. 
Gahvari, Firouz (1985), Taxation of housing, capital accumulation, and welfare: a study in dynamic tax reform, Public Finance Quarterly 13(2), 132-160.

Gervais, Martin (2002), Housing Taxation and Capital Accumulation, Journal of Monetary Economics 49(7), 1461-1489.

Gomme, Paul, Finn E. Kydland, and Peter Rupert (2001), Home Production Meets Time to Build, Journal of Political Economy 109(5), 1115-1131.

Greenwood, Jeremy and Zvi Hercowitz (1991), The Allocation of Capital and Time over the Business Cycle, Journal of Political Economy 99(6), 1188-1214.

Greenwood, Jeremy, Richard Rogerson and Randall Wright (1995), Household Production in Real Business Cycle Theory, in Cooley, Thomas (ed.) Frontiers of Business Cycle Research, Princeton University Press.

Hendershott, Patric H. and Michael White (2000), Taxing and Subsidizing Housing Investment: The Rise and Fall of Housing's Favored Status, Journal of Housing Research 11(2), 257-275.

Hendershott, P.H. and Y. Won (1992), Introducing Risky Housing and Endogenous Tenure Choice into a Portfolio-Based General Equilibrium Model, Journal of Public Economics 48, 293-316.

Jones, Larry E., Rodolfo E. Manuelli and Peter E. Rossi (1997), On the Optimal Taxation of Capital Income, Journal of Economic Theory 73, 93-117.

Judd, Kenneth L. (1985), Redistributive taxation in a simple perfect foresight model, Journal of Public Economics 28, 59-83.

Kydland, Finn (1995), Business cycles and aggregate labor market fluctuations, in Cooley, Thomas (ed.) Frontiers of Business Cycle Research, Princeton University Press. 
Lansing, Kevin J. (1999), Optimal redistributive capital taxation in a neoclassical growth model, Journal of Public Economics 73, 423-453.

McGrattan, Ellen R., Richard Rogerson and Randall Wright (1997), An Equilibrium Model of the Business Cycle with Household Production and Fiscal Policy, International Economic Review 38(2), 267-290.

Mendoza, Enrique G., Assaf Razin and Linda L. Thesar (1994), Effective tax rates in macroeconomics: Cross-country estimates of tax rates on factor incomes and consumption, Journal of Monetary Economics 34, 297-323.

Määttänen, Niku (2004), On the distributional effects of taxing housing, mimeo, Universitat Pompeu Fabra.

Poterba, James (1992), Taxation and Housing: Old Questions, New Answers, American Economic Review 82(2), 237-42.

Skinner, Jonathan (1996), The Dynamic Efficiency Cost of Not Taxing Housing, Journal of Public Economics 59(3), 397-417.

Slemrod, Joel (1982) Down-payment constraints: tax policy effects in a growing economy with rental and owner-occupied housing, Public Finance Quarterly 10(2), 193-217.

Turnovsky, Stephen J. and Toshiyuki Okuyama (1994), Taxes, housing and capital accumulation in a two-sector growing economy, Journal of Public Economics 53, 245-267. 